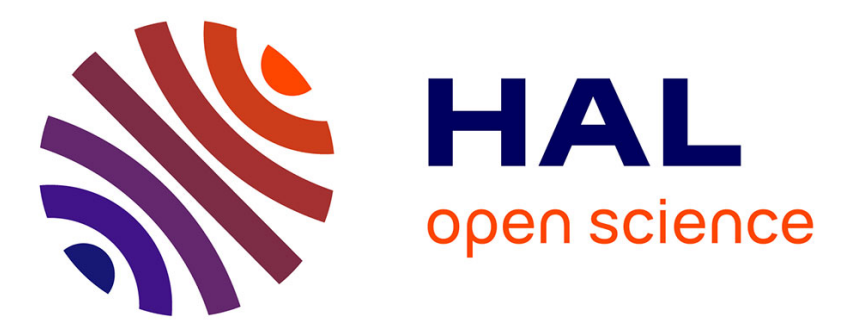

\title{
Structural defence is coupled with the leaf economic spectrum across saplings of spiny species
}

Mohammed Armani, Uromi Goodale, Tristan Charles-Dominique, Kasey Barton, Xin Yao, Kyle Tomlinson

\section{To cite this version:}

Mohammed Armani, Uromi Goodale, Tristan Charles-Dominique, Kasey Barton, Xin Yao, et al.. Structural defence is coupled with the leaf economic spectrum across saplings of spiny species. Oikos, 2020, 129, pp.740 - 752. 10.1111/oik.06960 . hal-02459703

\section{HAL Id: hal-02459703 \\ https://hal.science/hal-02459703}

Submitted on 17 Nov 2020

HAL is a multi-disciplinary open access archive for the deposit and dissemination of scientific research documents, whether they are published or not. The documents may come from teaching and research institutions in France or abroad, or from public or private research centers.
L'archive ouverte pluridisciplinaire HAL, est destinée au dépôt et à la diffusion de documents scientifiques de niveau recherche, publiés ou non, émanant des établissements d'enseignement et de recherche français ou étrangers, des laboratoires publics ou privés. 


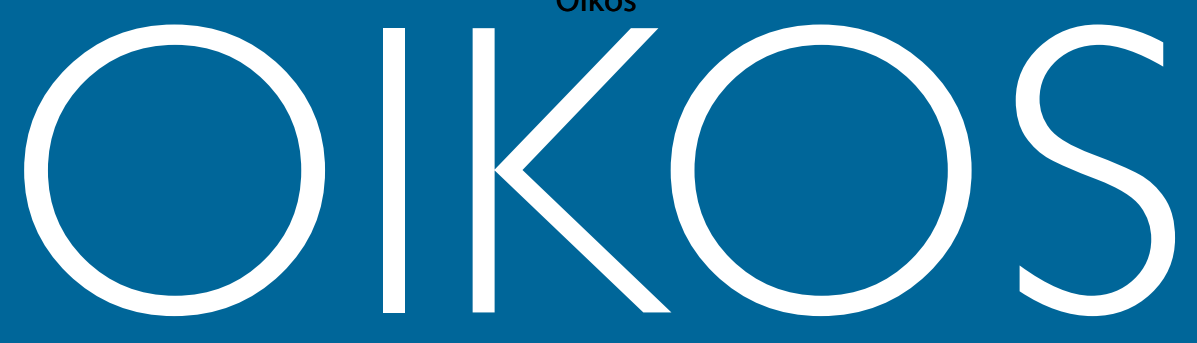

\title{
Research
}

\section{Structural defence is coupled with the leaf economic spectrum across saplings of spiny species}

5

\author{
Mohammed Armani, Uromi M. Goodale, Tristan Charles-Dominique, Kasey E. Barton, Xin Yao and \\ Kyle W. Tomlinson
}

10

M. Armani (https://orcid.org/0000-0002-1297-0296), X. Yao and K.W. Tomlinson (https://orcid.org/0000-0003-3039-6766) $\square$ (kylewtomlinson@ gmail.com), Center for Integrative Conservation, Xishuangbanna Tropical Botanical Garden, Chinese Academy of Sciences, Menglun, Mengla, CN-666303 Yunnan, PR China. MA also at: Univ. of Chinese Academy of Science, Beijing, PR China. - U. M. Goodale, Regeneration Ecology, Seed Bio-physiology and Conservation Laboratory, Plant Ecophysiology and Evolution Group, Guangxi Key Laboratory for Forest Ecology and Conservation, College of Forestry, Guangxi Univ., Nanning, Guangxi, PR China, and: State Key Laboratory for Conservation and Utilization of Subtropical Agro-Bioresources, Guangxi Univ., Nanning, Guangxi, PR China. - T. Charles-Dominique, Inst. of Ecology and Environmental Sciences - Paris, CNRS UMR 7618, Sorbonne Univ., 20 Paris, France. - K. E. Barton, Dept of Botany, Univ. of Hawaii at Manoa, Honolulu, HI, USA.

\section{Oikos}

25

00: $1-14,2020$

doi: $10.1111 /$ oik.06960

Subject Editor: Lonnie Aarssen Editor-in-Chief: Dries Bonte

30

Accepted 13 January 2020
Given that the rate of resource capture constrains plant growth and defence, understanding the linkage between the leaf economic spectrum (LES) and defence and how it contributes to growth is central to predicting species performance. In spite of the prevalence of spiny plants in many plant communities, little is known about how the LES relates to defence and growth rate across these species. We grew 42 spiny species, from diverse environments, under common garden conditions for 15 weeks and measured LES (leaf N, SLA and assimilation rate), defence and growth traits. We assessed general relationships between LES and growth rate and tested whether structural defences (spines, leaf fibre and lignin content) and quantitative chemical defences (condensed tannins) are linked to the LES and growth and if different spine types (i.e. leaf spines, stipular spines, prickles and thorns), with distinct anatomical origins, partition out across the LES. We observed two independent trait axes that together explained $\sim 68 \%$ of trait variation across species. The first axis showed that structural defences (spines, leaf fibre and lignin content) trade off with leaf productivity along the LES. Axis 2 revealed that condensed tannins is orthogonal and less integrated with the LES-structural defence axis. Bivariate trait analyses disclosed positive covariations between LES traits and sapling growth rate. All structural defence traits were negatively related to sapling growth. Across spine types, species with leaf spines were associated with the conservative end of the LES, characterized by high structural defences and lower leaf productivity relative to other spine types.

Synthesis: Our study shows that the LES and structural defences are coupled in spiny species such that constitutive growth - defence strategies range from fast-growing species with low allocation to defences to slow-growing species that invest heavily in structural defences (dominated by leaf spiny species).

Keywords: defence, growth-defence tradeoffs, growth rate, investment in spines, leaf economic spectrum, leaf productivity, spiny plant

@ 2020 Nordic Society Oikos. Published by John Wiley \& Sons Ltd 


\section{Introduction}

Plant growth rate and defence are fundamental determinants of species ecological performance (Herms and Mattson 1992, Salguero-Gómez 2017). Because plant growth rate and defence are strongly dependent on resource acquisition (Zuest and Agrawal 2017), there is a renewed interest in understanding how the leaf economic spectrum (LES) (Wright et al. 2004, Shipley et al. 2006) relates to the growth-defence axis

10 (Mason and Donovan 2015). The LES framework (Fig. 1a) identifies a trade-off in traits conferring higher leaf productivity (i.e. high leaf $\mathrm{N}$, high specific leaf area and assimilation rates; acquisitive strategy) against those enhancing leaf durability (e.g. low SLA and leaf N; conservative strategy).

15 Generally, acquisitive leaves are associated with fast-growing species (Fig. 1a) whereas slow-growing species tend to possess conservative leaves (Lambers and Poorter 1992, Shipley 2006, Reich 2014). The LES is also potentially linked to antiherbivore defence given that fast-growing species are thought to have low constitutive defences (Coley et al. 1985, Herms and Mattson 1992, Reich 2014). However, the extent to which the underlying traits are related, across species, remains poorly understood.

Generally, leaf structural defences (e.g. fibre content) and quantitative chemical defences (e.g. tannins) are expected to be linked to the LES (Fig. 1b; Coley et al. 1985, Onoda et al. 2017) due to their shared dependence on $C$ and $N$ investment (Mason and Donovan 2015). Leaf durability, a key aspect of the conservative strategy, is largely driven by high investment in structural C (e.g. cellulose) resulting in high leaf toughness or low SLA (Poorter et al. 2009, Kitajima and Poorter 2010, Kitajima et al. 2012, Onoda et al. 2017). Investment in leaf structural components also enhances leaf defences by increasing leaf toughness as well as reducing palatability and digestibility (Bryant et al. 1983, Coley et al. 1985, Hartley and Jones 1997, Moles et al. 2013). Consistent with this expectation, Mason and Donovan (2015) and Chauvin et al. (2018) have recently shown that structural defence traits, such as leaf

(a) Traits covariation along the leaf economic spectrum (LES)

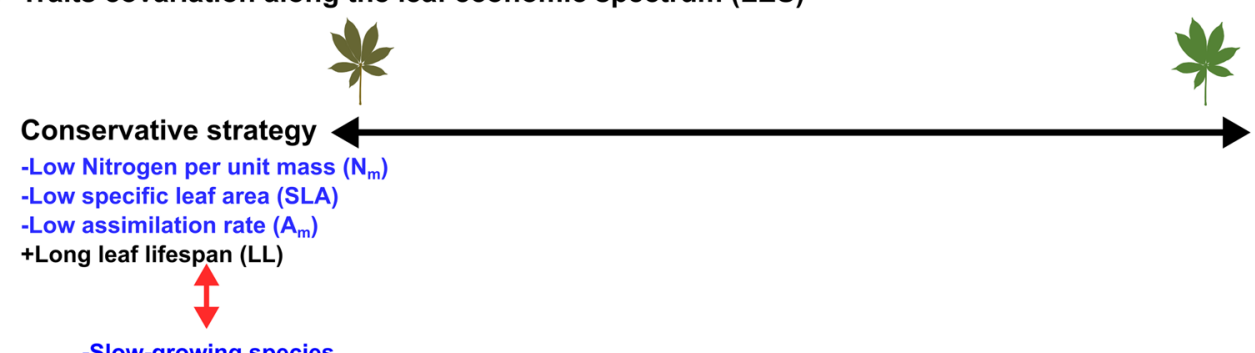

Acquisitive strategy +High Nitrogen per unit mass $\left(\mathrm{N}_{\mathrm{m}}\right.$ +High specific leaf area (SLA) +High assimilation rate $\left(A_{m}\right)$ -Short leaf lifespan (LL)

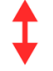

+Fast-growing species

(b) Hypothesized relationships between different defence traits and the LES
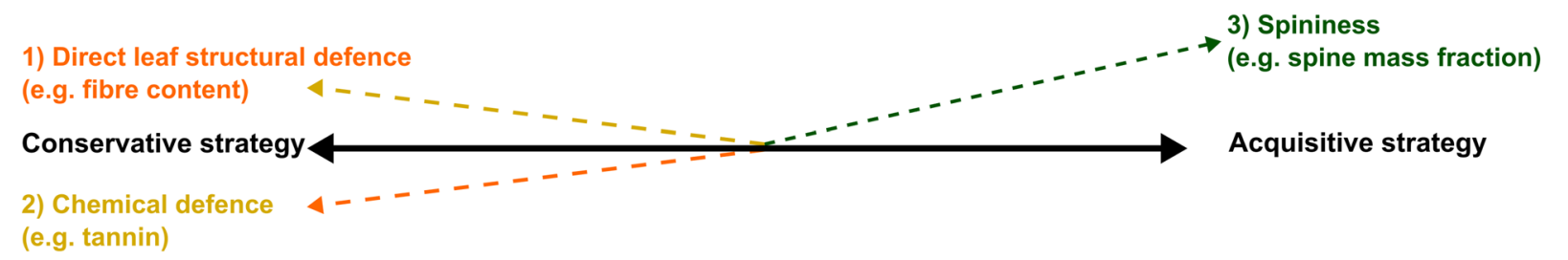

(c) Expected distribution of different spine types across the LES
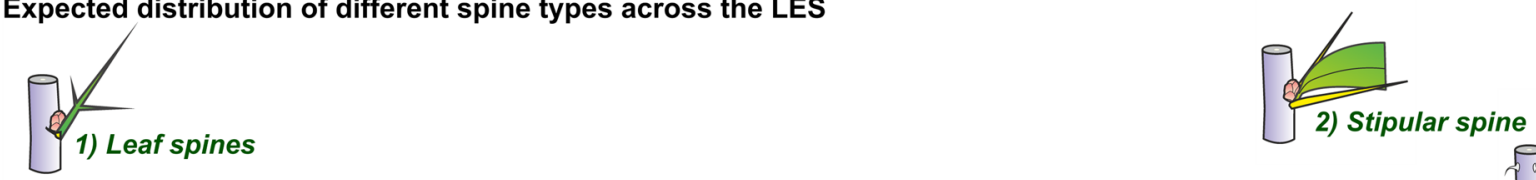

Conservative strategy
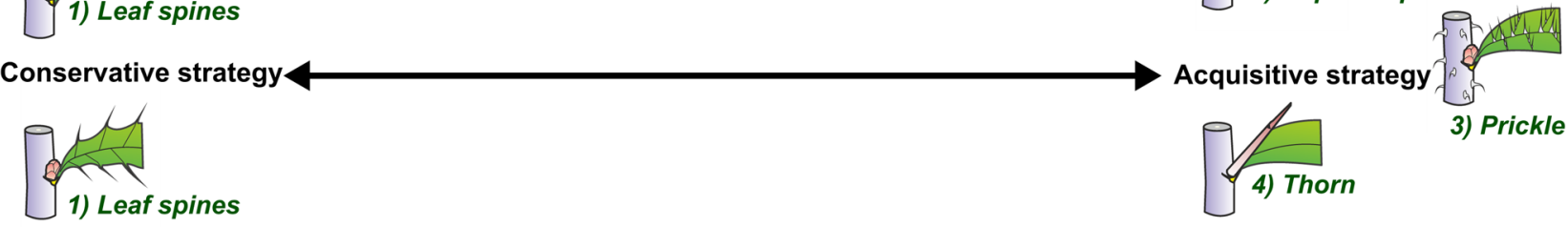

55 Figure 1. Conceptual framework of the relationships between different defence traits, spine types and the leaf economic spectrum (LES) traits. (a) Acquisitive leaf traits are generally associated with fast-growing species whereas conservative leaf traits are characteristic of slowgrowing species. (b) Leaf structural and quantitative chemical defence traits are predicted to be linked to the LES but have been assessed by only a few studies. Non-direct leaf defences, such as spines, may also be linked to the LES but so far have not been considered by studies that seeks to integrate the LES-defence-growth axes. (c) Species with different spine types are likely associated with different ends of the LES given the divergent implications of spine construction on leaf morphology and physiology. 
0 toughness and dry matter content, covary with the LES traits, being negatively correlated with leaf productivity (Fig. 1b-1).

Variations in leaf chemical defences, particularly quantitative defences (e.g. tannins), are predicted to be coupled with leaf lifespan such that long-lived leaves should be welldefended (Coley 1988). Given that longer leaf lifespan is associated with the conservative strategy, this suggests that greater investment in quantitative chemical defences should be associated with the conservative end of the LES spectrum (Fig. 1b-2). However, evidence for correlation between LES and quantitative chemical defence traits is equivocal. For instance, Mason and Donovan (2015) observed significant correlations between tannin activity and the LES axis in three Helianthus species across whole-plant ontogeny. In

15 contrast, Chauvin et al. (2018) observed that tannin content was decoupled from the LES axis in 83 species in a tropical moist forest in Panama. Thus, despite its importance to understanding carbon economy at the leaf-level, it remains unknown whether there is a consistent covariation between the LES traits and quantitative chemical defences. Here, we provide insights into the link between the LES, chemical and structural defences and sapling growth rate across a diverse set of spiny species. Spines are plant structural traits that func25 tion mainly as defences against large mammalian herbivores (Cooper and Owen-smith 1986, Hanley et al. 2007, but see: Kariyat et al. 2017). Spines differ from direct leaf structural and chemical defences (such as toughness or high fibre content) because they can function at either the individual

30 leaf-level (e.g. leaf spines and prickles) or whole plant level (e.g. thorns and stipular spines), especially in combination with 'cagey' branching (Archibald and Bond 2003, CharlesDominique et al. 2017). Thus, studying covariations between LES and defence traits in this group of species has the added advantage of providing further insights on whether and how the LES is integrated with defence at the whole-plant scale. Spiny species are widespread across terrestrial plant communities (Grubb 1992) and their evolution in Africa has been shown to be tightly linked to evolution and diversification of mammalian herbivores (Charles-Dominique et al. 2016). If defence is coupled with the LES and constrain leaf productivity in spiny plants, then ongoing changes in large mammalian herbivory pressure (Ripple et al. 2015, Hempson et al. 2017) may have major consequence for systems dominated by spiny plants given that mammalian herbivores impose significant constraints on sapling recruitment in these systems (Prins and van der Jeugd 1993, Augustine and McNaughton 1998, Staver and Bond 2014).

In contrast to direct leaf defences, spines seem to be associated with resource acquisitive life-history strategies (Fig. 1b-3; Grubb 1992, Tomlinson et al. 2016, Wigley et al. 2018). Within biomes, spiny species tend to possess nutritious and productive leaves (Grubb 1992), and are associated with greater resource sites (Milton 1991, Grubb 1992). For instance, Grubb (1992) noted that spiny species in closed forests are either predominantly pioneer gap-loving species that dominate tree-fall gaps (where both light and soil fertility are likely high) or associated with permanently open sites (e.g. rocky slopes or forest edges). Similarly, in African savannas, spiny species tend to possess high-quality fine-leaves often dominating nutrient rich soils (Scholes and Walker 2004, Charles-Dominique et al. 2016, Osborne et al. 2018) where large herbivore biomass is high (Hempson et al. 2015, Charles-Dominique et al. 2016). Recent studies have shown that the defence syndrome of spiny savanna species involves combining high leaf $\mathrm{N}$ with greater investment in spines with high/low chemical defences (Tomlinson et al. 2016, Wigley et al. 2018). Further, Rafferty and Lamont (2007) also found weak positive correlations between an index of 'spininess', leaf $\mathrm{N}$ and specific leaf area (SLA) for saplings of 19 species. Although these studies suggest that spines are associated with resource acquisitive life-history strategies (Fig. 1b-3), all the above analyses included both spiny and non-spiny species (i.e. species that never produce spines), potentially masking more subtle variation among different spiny plants in their productivity-defence trait relationships.

Different spine types are derived from different plant organs (Bell and Bryan 2008) and it is likely that producing these divergent spine types have differential effects on leaf morphology and physiology and hence their relationship with the LES (Fig. 1c). Spines can be derived from modified leaves (Fig. 1c-1; leaf spines), stipules (Fig. 1c-2; stipular spines), as outgrowths of the epidermis or cortex (Fig. 1c-3; prickles) or modified branches (Fig. 1c-4; thorns) (Grubb 1992, Gutschick 1999). Leaf spines may negatively affect leaf productivity, because greater fibre and lignin are required to modify leaf blades or margins into spines, and may be associated with resource conservative life-history strategies (Campbell 1986). Prickles and stipular spines generally incur low biomass allocation cost (Bazely et al. 1991, Armani et al. 2019) and although prickles can be produced on leaf surfaces, they have limited impact on leaf morphology and physiology (Björkman and Anderson 1990) and thus can be compatible with acquisitive leaf strategies. Similarly, although thorns incur significant biomass allocation cost relative to stipular spines or prickles and thus likely constrain growth rate (Armani et al. 2019), thorns are not directly linked to leaves and should be compatible with acquisitive leaf strategies. Therefore, different spine types likely partition out along the LES (Fig. 1c) but this notion has never been experimentally tested.

The aim of this study was to test whether different categories of defence traits (leaf structural defence, chemical defence and spines) are related to the LES and how these relationships are linked to sapling growth rate in spiny plants. In addition, we were interested in exploring whether species with distinct spine types partition out across the LES. Our approach was to select diverse spiny species (i.e. different spine types, plant families and contrasted environments; supplementary material Table 1) and grow them under common garden conditions for trait measurement. We measured eight traits that have been deomonstrated to be important for plant growth and defence (supplementary material Table 2). Relative 


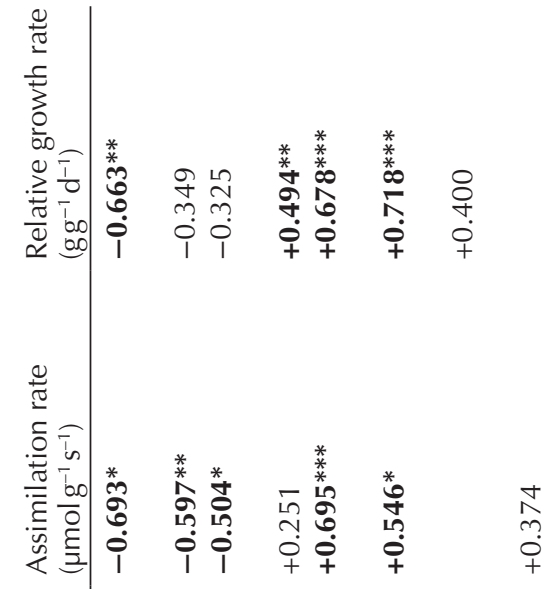

60

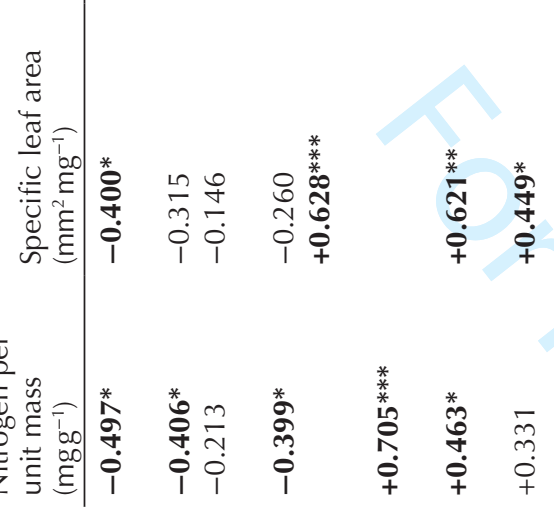

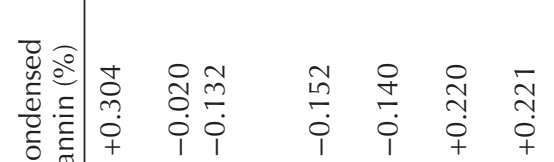

growth rate (RGR) is widely used as measure of plant performance (Evans 1972, Zuest and Agrawal 2017) and scales positively with acquisitive leaf traits (Lambers and Poorter 1992, Reich 2014). Specific leaf area (SLA), leaf N per unit mass $\left(\mathrm{N}_{\mathrm{m}}\right)$ and carbon assimilation per unit leaf mass $\left(\mathrm{A}_{\mathrm{m}}\right)$ are primary traits used in the LES and scale positively with each other (Wright et al. 2004). Spine mass fraction (SPMF) is a measure of biomass investment in spines (Bazely et al. 1991, Pisani and Distel 1998, Gowda and Palo 2003). Acid detergent fibre $(\mathrm{ADF})$ and lignin $(\mathrm{ADL})$ give measures of the least digestible fibre portion of plant material and are commonly used as indices of forage antiquality (Schindler et al. 2003, Rooke et al. 2004, Rafferty and Lamont 2007). Both lignin and fibre also generally contribute to low SLA and high leaf longevity (Poorter et al. 2009, Kitajima et al. 2012). Here, we classified $\mathrm{ADF}$ and $\mathrm{ADL}$ as structural defence trait. However, $\mathrm{ADF}$ and $\mathrm{ADL}$ are functionally similar to tannins in that their antiherbivore role involves reduction of digestibility and limiting the digestive energy of forages (van Soest 1982, Moore and Jung 2001). Condensed tannins (CT) are quantitative secondary metabolites (i.e. true chemical defence) that binds to protein making it unavailable to herbivores (Ayres et al. 1997, Wallis et al. 2012). Fibre, lignin and tannins are widespread across plant species (Mole 1993, Moore and Jung 2001), and are suitable common currencies for investigating trait-trait relationship across multiple species.

Specifically, we tested three main hypotheses (Fig. 1a-c). First, we predicted that across the studied taxa, acquisitive leaf traits (such as high leaf N, SLA and assimilation rate) will be associated with fast-growing species and vice versa (Fig. 1a). Secondly, we posited that all defence traits (spines, leaf chemical and structural defences; SPMF, ADF, ADL and CT) are linked to the LES across spiny species (Fig. 1b). However, we expected divergence between leaf structural and chemical defence traits (Fig. 1b1-b2; ADF, ADL and CT) and investment in spines (Fig. 1b3; SPMF) along the LES axis such that greater investment in spines will be associated with acquisitive life-history strategies whereas higher investment in leaf structural and quantitative chemical defences will be associated with the conservative life-history strategies. Finally, we hypothesized that species with different spine types will be associated with different ends of the LES. Specifically, we expected species with stipular spines, prickles and thorns to be more associated with the 'acquisitive end' of the LES whereas species with leaf spines will be characterized by conservative leaf traits.

\section{Material and methods}

\section{Seed collection}

We sampled seeds from the living collections of Xishuangbanna Tropical Botanical Garden of the Chinese Academy of Science (XTBG-CAS), located in Menglun, Yunnan, China $\left(21^{\circ} 55^{\prime} 38^{\prime \prime} \mathrm{N}, 101^{\circ} 15^{\prime} 6^{\prime \prime} \mathrm{E}\right)$; the XTBGCAS savanna field station in Yuanjiang Valley, Yunnan 
0 Table 2. Results of phylogenetic least squares (PGLS) models testing for differences in the relationships between defence, leaf productivity Q1 and growth rate for different spines types.*

\begin{tabular}{|c|c|c|c|c|c|c|c|c|c|}
\hline \multirow{3}{*}{$\begin{array}{l}\text { Trait-trait } \\
\text { relationship }\end{array}$} & \multicolumn{5}{|c|}{ Model summary } & \multicolumn{4}{|c|}{ Spine type replicates } \\
\hline & \multirow[b]{2}{*}{ Y-variable } & \multirow[b]{2}{*}{$\mathrm{X} \times$ Spine type } & \multicolumn{3}{|c|}{ F-values } & \multirow[b]{2}{*}{ Leaf } & \multirow[b]{2}{*}{ Prickle } & \multirow[b]{2}{*}{ Stipular } & \multirow[b]{2}{*}{ Thorn } \\
\hline & & & $x$ & Spine type & $\mathrm{X} \times$ Spine type & & & & \\
\hline \multirow[t]{3}{*}{ LES growth } & RGR & $\mathrm{Am}$ & $5.75^{*}$ & $7.36^{* *}$ & 0.70 & 0 & 6 & 5 & 8 \\
\hline & RGR & SLA & $5.35^{*}$ & 2.313 & 0.31 & 0 & 8 & 6 & 15 \\
\hline & RGR & $\mathrm{Nm}$ & $5.44 *$ & $3.92 *$ & 0.21 & 0 & 8 & 6 & 14 \\
\hline \multirow[t]{3}{*}{ Defence $\sim$ growth } & SPMF & RGR & $5.03 *$ & 1.99 & 0.90 & 0 & 6 & 6 & 4 \\
\hline & ADF & RGR & 0.57 & 0.14 & 0.15 & 0 & 8 & 6 & 14 \\
\hline & ADL & RGR & 0.03 & 0.74 & 0.06 & 0 & 8 & 6 & 14 \\
\hline \multirow[t]{13}{*}{ Defence $\sim$ LES } & $\mathrm{CT}$ & RGR & 1.34 & 1.59 & 0.44 & 0 & 8 & 6 & 14 \\
\hline & SPMF & $\mathrm{Nm}$ & $16.15^{* * *}$ & 1.9634 & 1.43 & 4 & 8 & 6 & 6 \\
\hline & SPMF & SLA & $13.24^{* *}$ & 1.04 & 1.74 & 4 & 8 & 6 & 8 \\
\hline & SPMF & $\mathrm{Am}$ & 0.46 & $21.42^{* *}$ & 2.64 & 0 & 5 & 5 & 2 \\
\hline & ADF & $\mathrm{Nm}$ & $6.74^{*}$ & 1.71 & 1.473 & 5 & 10 & 6 & 18 \\
\hline & ADF & SLA & 3.07 & 1.2 & 0.50 & 5 & 10 & 6 & 18 \\
\hline & ADF & $\mathrm{Am}$ & 0.00 & 0.25 & 0.02 & 0 & 6 & 5 & 8 \\
\hline & ADL & $\mathrm{Nm}$ & $4.79 *$ & 1.62 & 0.62 & 5 & 10 & 6 & 18 \\
\hline & ADL & SLA & 2.14 & 1.2 & 0.31 & 5 & 10 & 6 & 18 \\
\hline & ADL & $\mathrm{Am}$ & 0.05 & 0.65 & 0.41 & 0 & 6 & 5 & 8 \\
\hline & $\mathrm{CT}$ & $\mathrm{Nm}$ & 1.07 & $3.10^{*}$ & 1.69 & 5 & 10 & 6 & 18 \\
\hline & CT & SLA & 0.90 & $3.42 *$ & 1.18 & 5 & 10 & 6 & 18 \\
\hline & CT & $\mathrm{Am}$ & 0.93 & 0.48 & 2.25 & 0 & 6 & 5 & 8 \\
\hline \multirow{3}{*}{$\begin{array}{l}\text { Spine } \sim \text { chemical } \\
\text { defence }\end{array}$} & SPMF & ADF & 3.75 & 1.81 & 1.24 & 4 & 8 & 6 & 6 \\
\hline & SPMF & ADL & $5.22 *$ & 1.37 & 1.00 & 4 & 8 & 6 & 6 \\
\hline & SPMF & $\mathrm{CT}$ & 0.92 & 3.10 & 1.77 & 4 & 8 & 6 & 6 \\
\hline
\end{tabular}

Traits are measured on saplings of spiny species grown under greenhouse conditions for 15 weeks. SPMF, spine mass fraction; ADF, acid detergent fibre; ADL, acid detergent lignin; CT, condensed tannins; Nm, nitrogen per unit mass; SLA, specific leaf area; Am, assimilation rate; RGR, relative growth rate.

30 Model summary values are F-values derived from phylogenetically - adjusted analysis of variance (ANOVA). Significant relationships are shown as $\mathrm{p}<0.0001=* *, \mathrm{p}<0.001=* *, \mathrm{p}<0.05=*$.

Spine types with missing data (e.g. leaf spines) or insufficient replicates (i.e. $\mathrm{n}<4$; e.g. thorns) were excluded from these analyses.

$\left(23^{\circ} 28^{\prime} 15^{\prime \prime} \mathrm{N}, 103^{\circ} 10^{\prime} 37^{\prime \prime} \mathrm{E}\right)$; the Germplasm Bank of Wild

35 Species, Kunming Inst. of Botany (KIB-CAS); and from South Africa from an earlier experiment (Tomlinson et al. 2012). In total we sampled 42 species, most of which are native to tropical China and Southeast Asia (24 species) and Africa (13 species), and that naturally grow in 'open' (e.g. 40 savanna) or 'closed' (e.g. forest) from dry-wet environments (see Supplementary material Appendix 1 Table A1 for details). Of the 42 species (belonging to 17 plant families), 11 possessed prickles, 20 possessed thorns, five had leaf spines (all are Berberis species) and six had stipular spines.

\section{Greenhouse experiment}

Seeds were germinated either on agar or river sand, and ten (10) days after germination, they were transplanted into a greenhouse located in XTBG-CAS. The greenhouse was covered with shade netting from March to October to reduce irradiance levels to $40-50 \%$ of full sunlight to reduce desiccation and mortality of the young seedlings, particularly of

55 the forest species. Temperature and relative humidity in the greenhouse ranged from 19.7 to $33.3^{\circ} \mathrm{C}$ and 42 to $100 \%$, respectively. After germination, each individual seedling was transplanted into a plastic tube of $10 \mathrm{~cm}$ diameter and $80 \mathrm{~cm}$ length. We chose deep pots to allow space for taproot growth mixed with 18-6-12 N-P-K fertilizer (8-9 month mixture) at a concentration of $5 \mathrm{~kg}$ of fertilizer per $\mathrm{m}^{-3}$ of river sand. Each tube was irrigated two times daily with each irrigation event lasting one minute using an automated irrigation system.

Transplanted seedlings were allowed to grow for a minimum of 15 weeks (hereafter week 15, but ranged between 15 and 19 weeks) before trait analysis and harvest $(\mathrm{n}=357$ plants total). Previous research on a subset of the species indicated that size-related changes in traits stabilised by 15 weeks. For a subset of species, we also obtained biomass at five weeks of age (hereafter week 5 , but ranged between 5 and 8 weeks) to determine relative growth rate. For these 30 species (for which we had > 10 individuals; Supplementary material Appendix 1 Table A3), we randomly harvested five or more individuals (but three individuals for two species, a total of 225 individuals; Supplementary material Appendix 1 Table A3) at five weeks. For twelve species (including all species with leaf spines), we did not have enough individuals and therefore harvested all individuals of these species only during the final harvesting (Supplementary material Appendix 1 Table A3). The greenhouse experiment was conducted in two temporal blocks from July to December in both 2015 and 2016. Twelve species (two prickles, five stipular spines and five thorns) were grown in 2015, whereas 30 species (five 
0 leaf spines, nine prickles, one stipular spines and 15 thorns) were grown in 2016 (Supplementary material Appendix 1 Table A1). Greenhouse conditions (minimum, mean and maximum temperature and relative humidity) did not differ between 2015 and 2016 ( $p>0.05$ ) and thus temporal block was not considered in the analyses.

\section{Trait measurements}

Prior to harvesting at week 15 , we checked whether each plant bore spines or not (yes $=1$, no $=0$ ). For spine bearing individuals, we removed all spines on all plant organs. In all cases, we detached spines from the plant organ using either sharp razor blades or utility knives. Species with leaf spines often

15 produced whole-leaf modified spines, or spines were clearly visible as modified leaf-tips. For thorny plants, we included only modified branches with pointed and lignified tips (most species that produced thorns had only thorns emerging and few true branches, which were visually distinct). For species with prickles, we removed pickles from both the leaves and stem. For harvesting at both weeks 5 and 15 , we divided each harvested individual sapling into leaf, stem, root and spine (for spines, done only for week 15 as spines were not well developed at week 5). Root samples were oven-dried for $48 \mathrm{~h}$ at $65^{\circ} \mathrm{C}$, whereas leaf, stem and spines were dried for $72 \mathrm{~h}$ at $70^{\circ} \mathrm{C}$ (Perez-Harguindeguy et al. 2013). We combined all samples to obtain the sapling dry mass (g).

We measured RGR $\left(\mathrm{gg}^{-1} \mathrm{~d}^{-1}\right)$ following Tomlinson et al. $30 \quad(2014,2016)$ as the difference between the logarithm of final sapling mass (ln Mass ${ }_{15}$ ) and the logarithm of average initial mass at week five (ln Mass 5 ) divided by the growth interval (days). We determined RGR for 30 species out of the 42 species as we had no initial mass data for 12 of our species. We

35 estimated specific leaf area (SLA, $\mathrm{mm}^{-2}$ leaf area $\mathrm{mg}^{-1}$ leaf mass), mass-based assimilation rate $\left(\mathrm{A}_{\mathrm{m}}: \mu \mathrm{mol} \mathrm{CO}_{2} \mathrm{~g}^{-1} \mathrm{~s}^{-1}\right)$ and leaf nitrogen per unit mass $\left(\mathrm{N}_{\mathrm{m}}^{\mathrm{m}} ; \mathrm{mgg}^{-1}\right)$ following Perez-Harguindeguy et al. (2013). Before removing spines on leaves, we removed up to five healthy, fully expanded leaves from each individual and scanned one-sided surface area, for calculation of leaf area $\left(\mathrm{Lsa}, \mathrm{cm}^{2}\right)$. We computed the mean of these five leaves as the Lsa for each individual sapling. Each scanned leaf included midrib, all leaflets (for compound leaves) and petiole. Lsa was determined using ImageJ (Abràmoff et al. 2004). SLA was estimated by dividing the total area of scanned leaves by the total dry leaf mass $(\mathrm{Lsm})$. Area-based assimilation rate $\left(\mathrm{A}_{\mathrm{a}}, \mu \mathrm{mol} \mathrm{CO}_{2} \mathrm{~m}^{-2} \mathrm{~s}^{-1}\right)$ was measured with an open gas-exchange system at least one week before final harvesting of saplings. Measurements were made on 3-5 individuals for 19 species (due to unavailability of the LICOR during final harvesting of other species). During measurements, PPFD was set at $1500 \mu \mathrm{molm}^{-2} \mathrm{~s}^{-1}$ with an artificial light source, and vapour pressure deficit in the chamber was $<0.1 \mathrm{kPa}$. Measurements were made under ambient $\mathrm{CO}_{2}$ concentration with flow rates between 400 and $500 \mu \mathrm{mol} \mathrm{s}^{-1}$, and readings were taken after photosynthetic rates stabilised. Mass-based assimilation rate $\left(A_{m}\right.$ :
Photosynthetic traits were measured in December 2015 and 2016. Leaf nitrogen content $\left(\mathrm{N}_{\mathrm{m}} ; \mathrm{mgg}^{-1}\right)$ was quantified using the Dumas combustion method (Bremner 1965) with an elementar analyser.

We determined SPMF $\left(\mathrm{gg}^{-1}\right)$ as a ratio of total spine dry mass (leaf and stem spine) divided by total sapling dry mass $(n=26$, as spines were too few to allow accurate estimation of SPMF on four species, Supplementary material Appendix 1 Table A2). For estimation of ADF, ADL and CT (all in \%), dried leaves from all individuals of a species were pooled together for subsequent analysis (all spines on leaves were removed, as mentioned above, prior to chemical analysis). This was necessary because several species did not have enough leaf mass to allow for determination of these traits at the individual sapling level. ADF and ADL content were determined using a FOSS TM 2010 semi-automated system. Condensed tannin content was determined following the method described by Mole and Waterman (1987). Specifically, $2 \mathrm{~g}$ of dried, powdered leaf material was diluted with $80 \mathrm{ml}$ of distilled water in a $250 \mathrm{ml}$ conical flask. The flask was heated and the mixture allowed to boil for $30 \mathrm{~min}$ and subsequently centrifuged $\left(8000 \mathrm{r} \mathrm{min}^{-1}\right)$ for $4 \mathrm{~min}$. The supernatant was collected in a $100 \mathrm{ml}$ volumetric flask and diluted to volume. Five milliliter of Folin-Denis reagent was added followed by $3 \mathrm{ml}$ of sodium carbonate solution and diluted with $100 \mathrm{ml}$ of distilled water. The mixture was thoroughly mixed and allowed to settle, and absorbance was read at $765 \mathrm{~nm}$. All leaf chemical analyses were conducted at the Public Technology Service Centre (Central Laboratory) of Xishuangbanna Tropical Botanical Garden.

\section{Phylogenetic reconstruction}

We constructed a species-level phylogeny for our species to account for the possibility that the examined trait relationships may be driven by shared ancestry (Felsenstein 1985, Garamszegi 2014, Lajeunesse and Fox 2015). Here, phylogenetically-adjusted models were used only to ensure that our conclusions were not driven by relatedness in the sampled taxa and not to infer any evolutionary pattern. This is particularly important for spinescence for which some families, such as Fabaceae, contain a significant proportion of the spiny species and are also known for strategies that enhance their nitrogen acquisition. The current dataset is derived as part of a bigger ongoing project involving comparative trait analyses across sapling of both spiny and non-spiny plants. For this reason, we first constructed the species-level phylogeny for all the ninety two study species. The species-level phylogeny was constructed based on molecular sequence data of chloroplast $(r b c L$, matK, $t r n H-p s b A$ and $t r n L-t r n F)$ and combined ribosomal (ITS) gene regions downloaded from $<$ www.ncbi.nlm.nihh.gov>. Sequences for each molecular marker were aligned using MUSCLE (Edgar 2004). Aligned sequences were concatenated for phylogenetic Bayesian inference analysis using BEAST ver. 2.4.7 (Bouckaert et al. 2014). Best substitution models were tested by AIC using jModeltest ver. 2 (Guindon and Gascuel 2003, Darriba et al. 2015). 
0 Four chains were run for 20000000 iterations with the first 5000000 iterations discarded as burn-in and the remaining runs sampled at every 1000th iteration. Priors were set on some plant lineages to fix the phylogenetic topology according to the APG IV (APG 2016) after which a consensus tree was constructed. For the current analyses, we pruned the tree to include the forty two species of interest (Supplementary material Appendix 1 Table A4). We had no molecular sequence data for five of the 42 species. We manually inserted three species as polytomy within the related genera (all are Berberis species). We substituted Gmelina elliptica with G. villosa and dropped Cenocentrum tonkinense (because it is the only species from its genus; Supplementary material Appendix 1 Table A4).

\section{Statistical analyses}

We performed all analyses at the species level (by averaging traits per species) because individual-level data were unavailable for some traits (CT, ADL and $\mathrm{ADF}, \mathrm{N}_{\mathrm{m}}$ ). We first evaluated how traits were associated in multivariate space by performing a principal component analysis (PCA) using the 'prcomp' function. We excluded RGR and $A_{m}$ from the PCA analysis because of missing values for several species. To include all species in this analysis, species that did not produce spines were assigned an SPMF value of ' 0 '.

Subsequently, we tested for phylogenetic signals for each trait using Pagel's $\lambda$ (Pagel 1999), which quantifies the degree to which common descent of species describes the pattern of trait evolution across species. Pagel's $\lambda$ is expected to be ' 0 ' if there is no phylogenetic signal for a given trait but ' 1 ' when there is a strong phylogenetic signal (i.e. trait has evolved under Brownian motion assumption along the phylogeny)

35 (Pagel 1999, Kamilar and Cooper 2013). We estimated Pagel's $\lambda$ and assessed if the observed value significantly differed from ' 0 ' and ' 1 ' using a maximum likelihood ratio test implemented in the package 'carper' (Orme et al. 2018).

40 These analyses revealed strong phylogenetic signals in two traits.

We then examined bivariate relationships among and between defence (SPMF, ADF, ADL and CT), LES (SLA, $\mathrm{N}_{\mathrm{m}}, \mathrm{A}_{\mathrm{m}}$ ), and growth (RGR) traits using both ordinary and phylogenetic correlation analyses with both approaches producing qualitatively similar results (see Results). Ordinary pairwise trait-trait relationships were examined using the base R function 'cor.test'. Phylogenetic correlations were implemented using the 'phyl.vcr' function of the package 'phytools' (Revell 2012). To test whether bivariate relationships were contingent on spine type, we implemented phylogenetic least square (PGLS) regression models of the form: $\mathrm{Y} \sim \mathrm{ST} \times \mathrm{X}$; where $\mathrm{Y}=$ response trait (e.g. SPMF), $\mathrm{ST}=$ spine type and $\mathrm{X}=$ predictor trait (e.g. RGR) using the 'pgls' function of the 'caper' package (Orme et al. 2018). For each bivariate relationship, we included only species for which we measured both traits. Three traits (CT, SPMF and RGR) were significantly skewed whereas other traits showed slight this for all the above analyses. All statistical analyses were conducted in $\mathrm{R}$ ver. 3.4.4 (<www.r-project.org $>$ ).

\section{Results}

\section{Emergence and biomass investment in spines}

Of the 42 species included in our study 30 produced spines by the time of harvesting at week 15 whereas eleven thornbearing species (out of 20) and one prickle-bearing species did not produce spines during our experiment (Fig. 2). Across species, investment in spines (SPMF) ranged from $0.01 \%$ to $9.4 \%$ of total sapling mass and was substantially more variable (187-fold) than any other measured traits (varied from 2.8 to 27.6-fold, Supplementary material Appendix 1 Table A2).

\section{Influence of phylogeny on trait distribution}

Two of the LES traits ( $A_{m}$ and SLA) showed strong phylogenetic signal (Pagel's $\lambda$ for all $>0.9$; and likelihood ratio test indicated that estimated $\lambda$ was different from $0, p<0.001$ but not 1; $>>0.05$, Fig. 2, Supplementary material Appendix 1 Table A2), suggesting that these traits were not independent of phylogeny in our dataset.

\section{Multivariate trait covariations across spiny species}

Trait associations in multivariate space suggested that, across species (using our full dataset, $n=42$ ), investment in structural defence (both leaf structural defence and spines) is negatively linked to the LES. The first PCA axis (which explained 46\% of the variation in trait composition; Fig. 3) separated species with high investment in structural defences (i.e. SPMF, ADF, $\mathrm{ADL}$ ) on the right from those with high leaf productivity traits (i.e. $\mathrm{N}_{\mathrm{m}}$ and SLA) on the left. Hence this axis represents a 'LES - structural defence' spectrum with a separation between species possessing thin leaves with high nitrogen content (including species such as Senegalia pennata, Vachellia farnesiana and Flueggea virosa) from species with thick leaves that had high leaf fibre/lignin content and strongly defended by spines (e.g. Berberis spp, Flacourtia indica, Carissa macrocarpa). A second axis (PCA axis 2, explained $22.4 \%$ of the variation in trait composition, Fig. 3) discriminated species with high investment in condensed tannin content from species with both high leaf structural defences (ADF and ADL) and high leaf productivity $\left(\mathrm{N}_{\mathrm{m}}\right.$ and SLA; Fig. 3).

\section{Bivariate relationships among traits}

Pairwise trait-trait analyses showed strong positive covariations among the LES traits (Table 1). Generally, all LES traits were significantly (except assimilation rate) and positively related to sapling growth rate. Investment in spines (SPMF) was positively (but not significant for phylogenetic correlation analyses) related to all other defence traits whereas fibre 


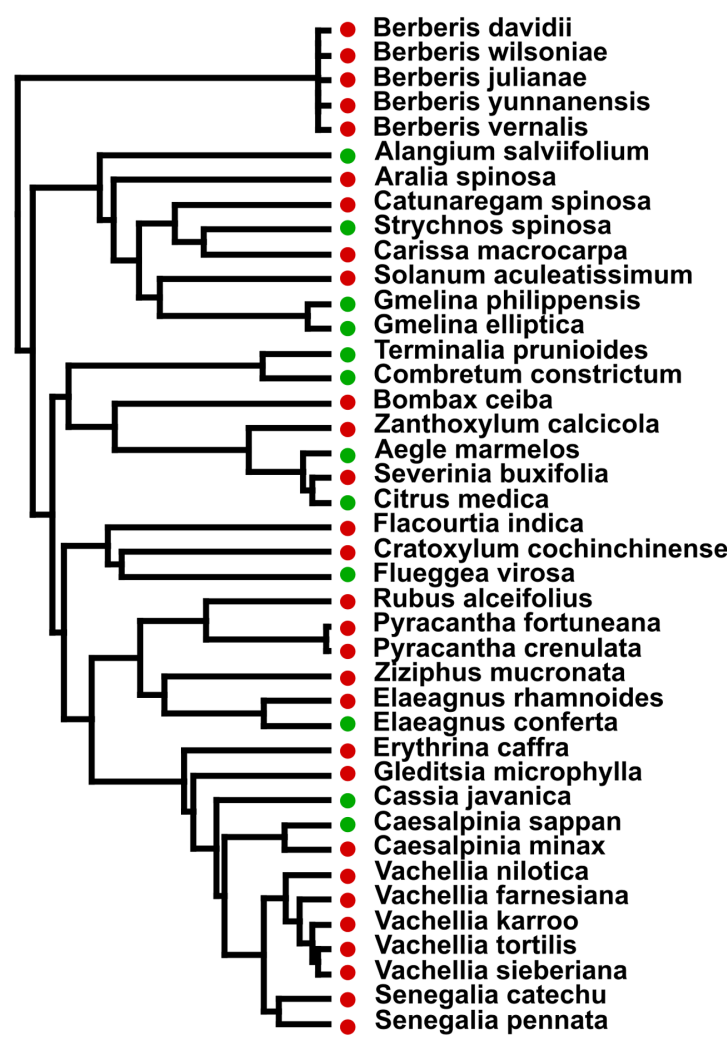

30

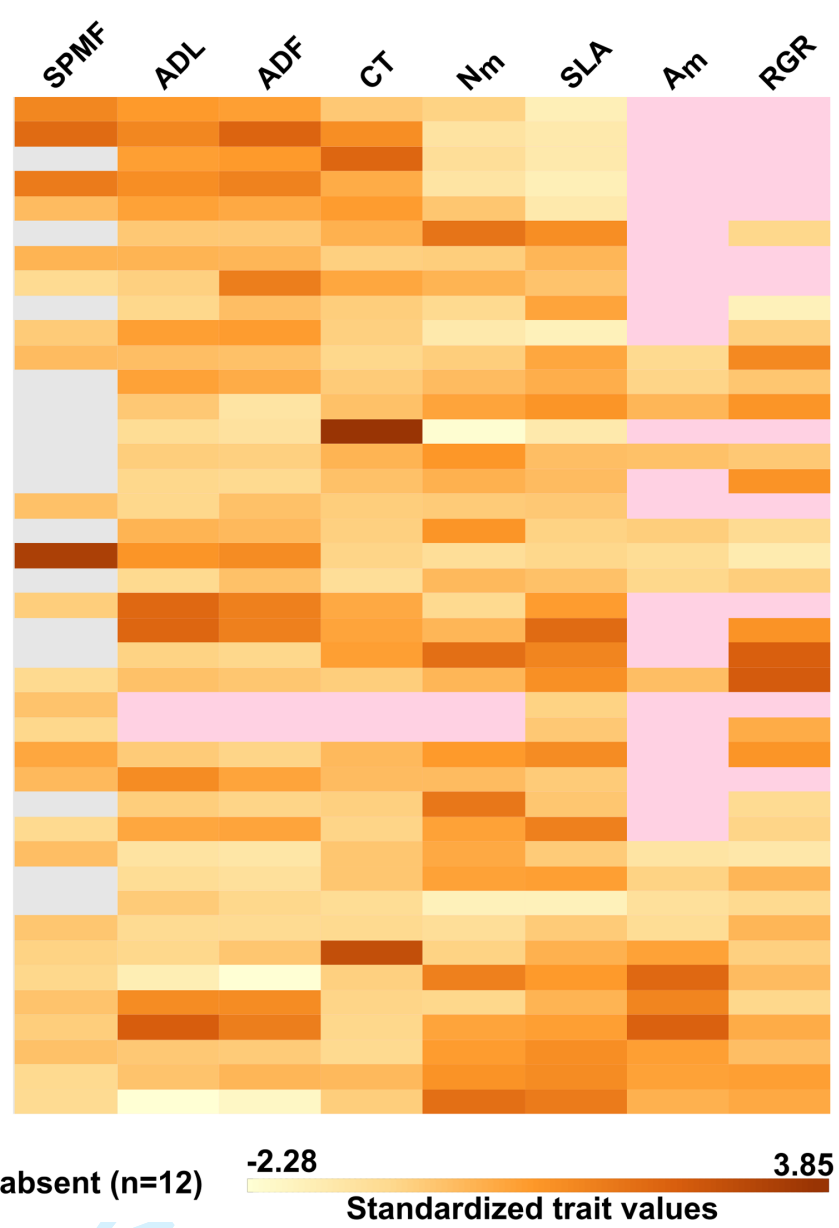

Standardized trait values

Figure 2. Phylogenetic tree showing trait distribution across the 41 (of 42) species included in this study. Traits values are standardized. Light pink color represent missing data. Light gray color in SPMF represents species that did not produce spines. Traits are: SPMF, spine mass fraction; ADF, acid detergent fibre; ADL, acid detergent lignin; CT, condensed tannins; Nm, nitrogen per unit mass; SLA, specific leaf area; Am, assimilation rate; RGR, relative growth rate. Red and green filled dots on phylogeny represent spiny species that produced or did not produce spines during experimental period.

$(\mathrm{ADF})$ and lignin (ADL) contents were unrelated to condensed tannins (CT) (Table 1). All defence traits were negatively related to the LES traits (except for a non-significant positive correlation between CT and Am), providing further support to the finding that that defences tradeoff with leaf productivity (Table 1, Fig. 3). Across species (excluding species with leaf spines which lacked RGR data), growth rate was positively related with condensed tannins content (CT; $r=0.494 ; p<0.005$, for the phylogenetic correlation) but negatively related to all other defence traits (Table 1).

\section{Strategies across spine types}

Exploration of the multivariate trait space, using PERMANOVA (Anderson 2017), indicated significant differences in the multidimensional trait space of the different spine types $(F=3.15, p=0.002)$. Specifically, species possessing leaf spines were separated in ordination space from the other spine types and were more associated with the 'high structural defence' end of the spectrum (Fig. 4). We further tested whether bivariate relationships among traits were contingent on spine types (leaf spine, stipular spine, prickles and thorns). While the intercept of few (5 out of 23) trait-trait relationships differed by spine type (i.e. additive effects), none of the slopes of these relationships were significantly different (Table 2).

\section{Discussion}

In this study, we examined the links between the leaf economic spectrum (LES), structural defences (spines, leaf fibre and lignin content), quantitative chemical defence (condensed tannins) and sapling growth rate across a diverse set of spiny species ( 42 species) encompassing a broad taxonomic scope (17 families). Given that spines derived from distinct organs likely have differential effect on leaf morphology and physiology, we also tested whether species with different spine types partitioned out along the LES given. We found two independent trait axes that together explained $\sim 68 \%$ of 


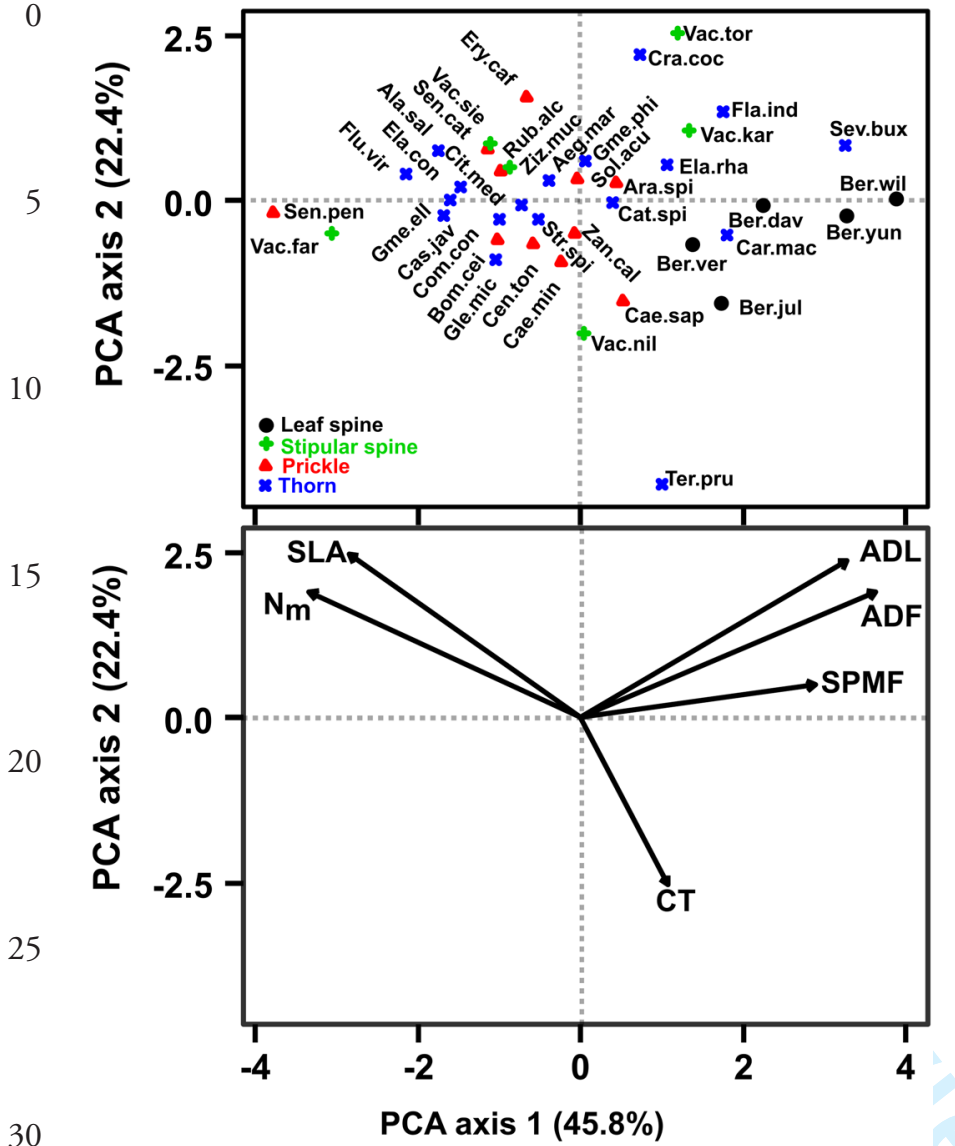

Thin leaves, high leaf productivity

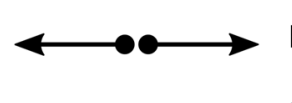

Thick leaves, high investment in spines and chemical defences

Figure 3. Principal component analysis (PCA) of multivariate trait associations of saplings of 42 spiny species. (a) Biplot of species score on first two PCA axes. Species names are abbreviations of first three letters of 'Genus.species' names (e.g. Sen. pen = Senegalia pennata). Symbols for different spine types shown in legend. (b) Biplot of factor loadings for traits on the first PCA axes. Leaf productivity traits; specific leaf area (SLA) and Nitrogen content per unit leaf mass $\left(\mathrm{N}_{\mathrm{m}}\right)$; defence traits; spine mass fraction (SPMF), acid detergent fibre (ADF) and lignin (ADL), condensed tannins (CT).

trait variations across species. The first axis showed that the leaf economic spectrum (LES) and structural defences are linked in spiny plants. The second axis discriminated species with high investment in condensed tannins from species with both high leaf structural defences (lignin and fibre content) and high leaf productivity. Bivariate trait analyses confirmed that LES traits positively covary with sapling growth rate. Importantly, our analyses disclosed positive synergies between spines and leaf structural defence traits (fibre and lignin) whereas leaf structural defence traits were less integrated with condensed tannins (a measure leaf chemical

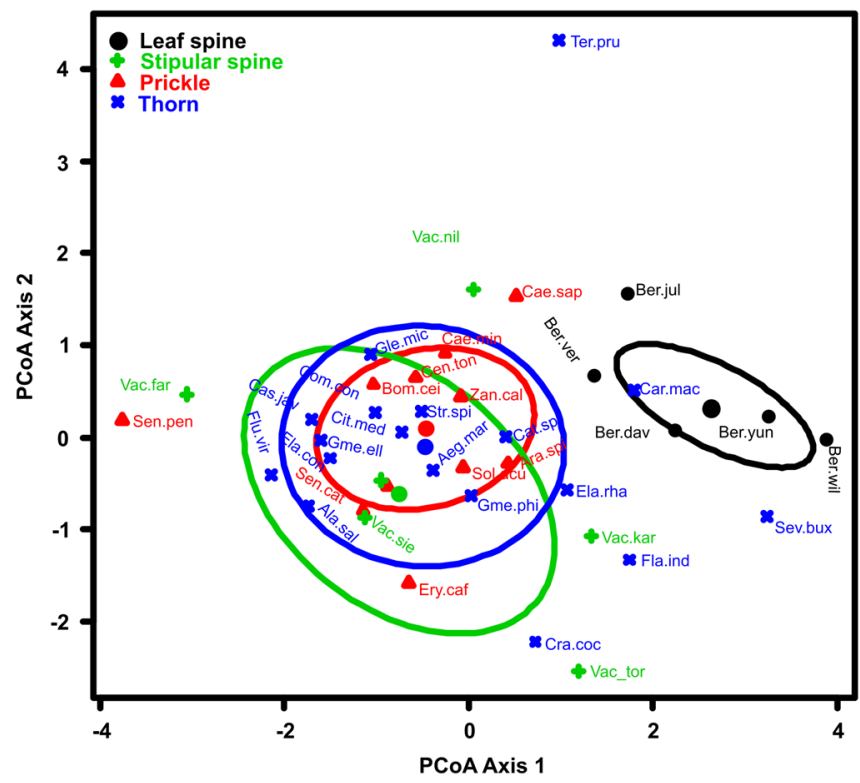

Figure 4. Principal coordinate analysis (PCoA) of multivariate trait associations of saplings of 42 spiny species. Species names are abbreviations of first three letters of 'Genus.species' names (e.g. Sen. pen $=$ Senegalia pennata). Symbols for different spine types shown in legend. Centroid of each spine type indicated with large filled circles. Broken ellipses enclose $95 \%$ confidence intervals of trait space for each spine types. Inserted table is summary results of pairwise comparison of the trait space between spine types. Differences in multivariate trait space are denoted with $\mathrm{p}<0.001\left(^{* * *}\right), \mathrm{p}<0.01$ $\left.{ }^{* *}\right), \mathrm{p}<0.05\left(^{*}\right)$ and $\mathrm{p}>0.05$ (ns = no significant difference between groups).

related to the LES traits and sapling growth. Thus, the general constitutive growth - LES - structural defence spectrum observed in this study is consistent with predictions from plant defence and the leaf economic spectrum theories that slow-growing species are selected for low leaf productivity and greater investment in constitutive defences (Coley et al. 1985, Herms and Mattson 1992, Stamp 2003, Wright et al. 2004). Across spine types, species with leaf spines were associated with the conservative end of the LES, being characterized by high structural defences and lower leaf productivity relative to other spine types.

\section{General patterns in LES, defence and growth trait covariations across spiny species}

Our analyses disclosed that structural defence (spine, leaf fibre and lignin) and LES axis (leaf N, SLA and assimilation rate) were coupled in spiny plants (Fig. 3). This finding is consistent with previous studies reporting that leaf structural traits are physiologically linked to the LES (Hallik et al. 2009, Mason and Donovan 2015, Chauvin et al. 2018). Leaf productivity (e.g. carbon assimilation rate) is determined to a large extent by leaf N and SLA (Wright et al. 2004, Reich et al. 2012, Díaz et al. 2015) and both leaf N and SLA are expected to tradeoff with investment in leaf structural 
0 defence (Westoby et al. 2002, Wright et al. 2004, Reich et al. 2012, Onoda et al. 2017). Both lignin and fibre are also expected to contribute to low SLA (or high leaf mass per unit area = LMA) (Poorter et al. 2009, Kitajima et al. 2012, Onoda et al. 2017). Consistently, we observed strong positive correlations between LES traits and negative correlations between all structural defence traits and LES traits (Table 1).

Condensed tannin (CT) content was less integrated with the LES-structural defence axis, suggesting that quantitative chemical defences may have evolved independently of the LES or structural defences in spiny species. Across multivariate trait space, CT was orthogonal to the LES-structural defence axis (Fig. 3). Further, bivariate trait analyses (Table 1) showed mostly non-significant correlations between CT

15 and other defence traits. These findings contradict the expectation that leaf-level allocation to immobile quantitative defences trades off with leaf productivity (Wright et al. 2004, Poorter et al. 2009) and should be linked to conservative strategy (Coley et al. 1985). Similar to our results, a recent study, on 83 moist tropical forest species in Panama, also observed that tannin content (both condensed and hydrolysable tannin) was decoupled from the LES (Chauvin et al. 2018). In contrast, Mason and Donovan (2015) showed that tannin activity (\% tannic acid) was strongly correlated with the LES axis in three Helianthus species across ontogeny. It is possible that within species or clades trade-off between quantitative defences and leaf productivity may exist, however across distantly related taxa, fundamental differences in 30 leaf chemistry may override any general patterns (Moles et al. 2013, Agrawal and Weber 2015). Given the limited literature, further studies across different plant species and from diverse systems are required to confirm whether chemical defence traits are coupled or decoupled from the LES.

Investment in spines scaled negatively with leaf productivity (Fig. 3, Table 1) in contrast to previous studies that reported positive association between spininess and leaf productivity (Rafferty and Lamont 2007, Wigley et al. 2018).

40 The contrasting results might stem from differences in the ontogenetic stage (adult versus saplings) or taxonomic scope (e.g. our study includes only spiny species whereas previous analyses included both spiny and non-spiny species). For instance, Wigley et al. (2018) has recently shown that across adult savanna species, moderate to high investment in spines (measured as average spine density; spines $\mathrm{cm}^{-1}$ ) is associated with species with greater available leaf $\mathrm{N}$, suggesting a potential switch in strategy from saplings to adults. Indeed, Mason and Donovan (2015) have recently demonstrated that changes in leaf productivity (i.e. LES strategy) during wholeplant ontogeny, in three sunflower species, may be driven by changes in leaf physical and chemical defences. Thus, across spiny and non-spiny species greater leaf $\mathrm{N}$ in spiny species may cause positive correlations between investment in spines and leave productivity. However, within spiny species, our findings suggest that greater leaf productivity tradeoff with investment in spines.
It is still debated whether alternative defence types (e.g. structural versus chemical defence) tradeoff or are coordinated across species (Agrawal and Fishbein 2006, Read et al. 2009, Moles et al. 2013, Barton 2014). Here, our analyses on a diverse set of spiny plants suggest that different structural defence traits (i.e. spines versus leaf fibre and lignin content) may be coordinated whereas chemical defence is independently expressed (Fig. 3). Generally, across spiny species, there is little evidence of tradeoff between chemical and structural defences with most studies observing synergies (Twigg and Socha 1996, Hanley and Lamont 2002) or no correlations (Pisani and Distel 1998, Rafferty and Lamont 2007, Barton 2014). The coordination of spines and leaf lignin and fibre content in spiny plants may have adaptive value. Firstly, building spines requires fiber and lignin (Hanley et al. 2007, Kellogg et al. 2011). Thus, species selected for greater investment in spines may be inherently predisposed to have greater leaf fiber and lignin content. Secondly, simultaneous expression of spines and leaf structural defences may be desirable for saplings growing in risky environments (i.e. where cost of herbivory may be high) (Bryant et al. 1983, Coley et al. 1985, Read et al. 2009).

\section{Syndromes across spine types}

Across multivariate trait space, a spectrum of constitutive LES - structural defence strategies in spiny saplings emerged (Fig. 3). At one extreme end of the continuum, the strategy consists of plants with high structural defences and low leaf productivity, consistent with the 'low nutrition, high resistance' syndrome (Agrawal and Fishbein 2006). This strategy was most characterized by species with leaf spines (Fig. 4). Species on the opposite end of the spectrum are characterised by a syndrome of low investment in structural defences and high leaf productivity (consistent with the 'tolerance and escape' defence syndrome) (Agrawal and Fishbein 2006). Most species with prickles, thorns and stipular spines aligned along this end of the spectrum. These results indicate that spiny species with leaf spines may predominantly adopt the low leaf productivity and high structural defence strategy (Campbell 1986) relative to other spine types. However, this result should be interpreted with caution given that all leaf spiny species in our dataset are from a single plant Genus (Berberis).

Generally, the directions (i.e. positive or negative associations) of the relationship among traits were not contingent on spine types (Table 2). Even for the trait-trait relationships for which we observed significant differences (in the intercepts) between the spine types, the directions of the relationships were always the same. Thus, all spine types (leaf spine, stipular spine, prickles and thorns) seems to exhibit a common strategy irrespective of their contrasting anatomical pathways (i.e. modified leaves, stipules, epidermis or branch). In spite of this, the intercept of the relationships between 'growth leaf $\mathrm{N}$ ' and 'growth - assimilation rate $\left(\mathrm{A}_{\mathrm{m}}\right)$ ' differed across spine types (Table 2). Generally, species with prickles had greater growth rate at a given leaf $\mathrm{N}$ or assimilation rate 
0 relative to species with stipular spines or thorns (data not shown). This suggests that species with different spine types may have different growth efficiencies. However, given that the relationship between growth rate or LES and defence traits did not differ across spine types (Table 2), the difference in growth efficiencies between the spine types may be driven by other unmeasured traits (e.g. leaf size or biomass allocation) (Tomlinson et al. 2014).

\section{Study limitations and recommendations for further studies}

Our results should be interpreted with caution for two main reasons. First, species were grown under a single common

15 garden lacking any herbivore. Thus, trait covariations presented in this study is relevant at the constitutive level. A substantial body of literature has shown that spines, like most other defence traits (Cipollini et al. 2003, Heil 2014), are inducible i.e. greater resources allocated to spines under herbivory conditions (Milewski et al. 1991, Obeso 1997, Young and Okello 1998, Gómez and Zamora 2002, Young et al. 2003, Hanley et al. 2007, Barton 2016). Similarly, leaf traits such as nitrogen content, SLA and assimilation rate can be altered under herbivory conditions (Zhou et al. 2015, Peschiutta et al. 2018). Second, our analyses focused only on spiny plants, because one of our aims was to understand whether and how spines (which function differently from direct leaf defence traits such as tannins and lignin) are related 30 to the LES. By focusing on spiny plants, our analyses do not provide information how LES and defence traits covary in non-spiny plants. However, in nature, spiny and non-spiny plants co-occur across biomes and experience similar growth constraints (Grubb 1992, Schmidt et al. 2013, Tindall et al. 2016).

Despite the above-mentioned limitations, our results have elucidated some of the general trends in LES - defence trait covariations. For instance, although focusing only on spiny plants, our results are consistent with that of Chauvin et al. (2018), who explicitly studied LES-defence traits in 83 moist tropical forest species (some species in the study area were spiny but this study did not consider spininess). While only few studies have evaluated the links between defence and 45 the LES (Zuest and Agrawal 2017), the convergence of our results and those of Chauvin et al. (2018) suggests, that across species, structural defence and the LES are linked whereas quantitative chemical defence are decoupled from this axis. In spite of this, we recognize that further studies testing the generality of the trait-trait relationships observed in this study, under natural conditions, across different biomes and comparing between plant functional groups will be particularly insightful for developing an integrative framework for understanding LES-defence trait covariations.

\section{Conclusion}

We conducted a large-scale common garden study to exam60 ine the links between the LES, defence (structural and quantitative chemical defences) and growth in saplings of spiny species. Generally, our results demonstrate that structural defence traits (spines, leaf lignin and fibre content) are coupled with the LES but are decoupled from quantitative chemical defence. Importantly, the most productive spiny species (high leaf productivity and fast growth rate) were associated with low constitutive investment in structural defences. Leaf spiny species in our dataset were more commonly associated with the high structural defence and low leaf productivity end of the spectrum relative to other spine types. Understanding how the observed traits syndromes vary across biomes, plant functional groups and ontogeny will be particularly helpful in providing insights for predicting how spinescent species are likely to respond to changes in herbivory and environmental resource supply.

\section{Data availability statement}

Data are available from the Dryad Digital Repository: $<$ http://dx.doi.org/10.5061/dryad.xxxxx> (Armani et al. 2020).

Acknowledgements - The authors thank Yang Dong, Yejin Wang, staff of the Germplasm Bank of Wild Species (Kunming Institute of Botany - Chinese Academy of Science) for their helpful support throughout this study.

Funding - The project was funded by a research grant from the National Natural Science Foundation of China (grant no. 31470449) and Guangxi 100 Talent Grant to Uromi M. Goodale. Mohammed Armani is supported by a Chinese Government scholarship.

Conflict of interest - There is no potential conflict of interest to be disclosed by the authors.

Author contributions - KWT and MA conceived the study. MA and UG collected the data. XY conducted the phylogenetic reconstruction. MA analysed the data and led the writing of the manuscript. KWT, UG, TCD, XY and KEB contributed critically to the drafts and gave final approval for publication.

\section{References}

Abràmoff, M. D. et al. 2004. Image processing with ImageJ, 2nd edn. - Biophotonics Int. 11: 36-42.

Agrawal, A. A. and Fishbein, M. 2006. Plant defense syndromes. - Ecology 87: S132-S149.

Agrawal, A. A. and Weber, M. G. 2015. On the study of plant defence and herbivory using comparative approaches: how important are secondary plant compounds. - Ecol. Lett. 18: 985-991.

Anderson, M. J. 2017. Permutational multivariate analysis of variance (PERMANOVA). - In: Wiley StatsRef: statistics reference online. Wiley, pp. 1-15.

APG. 2016. An update of the Angiosperm Phylogeny Group classification for the orders and families of flowering plants: APG II. - Bot. J. Linn. Soc. 141: 399-436.

Archibald, S. and Bond, W. J. 2003. Growing tall vs growing wide: tree architecture and allometry of Acacia karroo in forest, savanna and arid environments. - Oikos 1: 3-14. 
0 Armani, M. et al. 2019. Developmental constraints and resource environment shape early emergence and investment in spines in saplings. - Ann. Bot. in press.

Armani, M. et al. 2020. Data from: Structural defence is coupled with the leaf economic spectrum across saplings of spiny species. - Dryad Digital Repository, <http://dx.doi.org/10.5061/ dryad.xxxxx>.

Augustine, D. J. and McNaughton, S. J. 1998. Ungulate effects on the functional species composition of plant communities: herbivore selectivity and plant tolerance. - J. Wildl. Manage. 64: 1165-1183.

Ayres, M. P. et al. 1997. Diversity of structure and antihebivore activity in condensed tannins. - Ecology 78: 1696-1712.

Barton, K. E. 2014. Prickles, latex and tolerance in the endemic Hawaiian prickly poppy (Argemone glauca): variation between populations, across ontogeny and in response to abiotic factors. - Oecologia 174: 1273-1281.

Barton, K. E. 2016. Tougher and thornier: general patterns in the induction of physical defence traits. - Funct. Ecol. 30: 181-187.

Bazely, D. R. et al. 1991. The response of numbers of bramble prickles to herbivory and depressed resource availability. Oikos 61: 327-336.

Bell, A. D. and Bryan, A. 2008. Plant form: an illustrated guide to flowering plant morphology. - Timber Press.

Björkman, C. and Anderson, D. B. 1990. Tradeoff among antiherbivore defences in a south american blackberry (Rubus bogotensis). - Oecologia 85: 247-249.

Bouckaert, R. et al. 2014. BEAST 2: a software platform for bayesian evolutionary analysis. - PLoS Comput. Biol. 10: 1-6.

Bremner, J. M. 1965. Total nitrogen. - In: Norman, A. G. (ed.), Methods of soil analysis. Part 2. Chemical and microbiological properties. Agronomy monograph SV - 9.2. Am. Soc. Agron., Soil Sci. Soc. Am.a, pp. 1149-1178.

Bryant, J. P. et al. 1983. Carbon/nutrient balance of boreal plants in relation to vertebrate herbivory. - Oikos 40: 357-368.

Campbell, B. M. 1986. Plant spinescence and herbivory in a nutrient poor ecosystem plant spinescence and herbivory in a nutrient poor ecosystem. - Oikos 47: 168-172.

Charles-Dominique, T. et al. 2016. Spiny plants, mammal browsers and the origin of African savannas. - Proc. Natl Acad. Sci. USA 113: E5572-E5579.

40 Charles-Dominique, T. et al. 2017. The architectural design of trees protects them against large herbivores. - Funct. Ecol. 31: 1710-1717.

Chauvin, K. M. M. et al. 2018. Decoupled dimensions of leaf economic and anti-herbivore defense strategies in a tropical canopy tree community. - Oecologia 186: 765-782.

Cipollini, D. et al. 2003. Costs of induced responses in plants. Basic Appl. Ecol. 4: 79-89.

Coley, P. D. 1988. Effects of plant growth rate and leaf lifetime on the amount and type of anti-herbivore defense. - Oecologia 74: 531-536.

Coley, P. D. et al. 1985. Resource availability and plant antiherbivore defense. - Science 230: 895-899.

Cooper, S. M. and Owen-smith, N. 1986. Effects of plant spinescence on large mammalian herbivores. - Oecologia 68: 446-455.

Darriba, D. et al. 2015. jModelTest 2: more models, new heuristics and high-performance computing. - Nat. Methods 9: 6-9.

Díaz, S. et al. 2015. The global spectrum of plant form and function. - Nature 529: 167-171.
Edgar, R. C. 2004. MUSCLE: multiple sequence alignment with high accuracy and high throughput. - Nucleic Acids Res. 32: 1792-1797.

Evans, G. C. 1972. The quanitative analysis of plant growth. Blackwell Scientific Publications.

Felsenstein, J. 1985. Phylogenies and the comparative method. Am. Nat. 125: 1-15.

Garamszegi, L. Z. 2014. Uncertainties due to within-species variation in comparative studies:measurement errors and statistical weight. - In: Garamszegi, L. Z. (ed.), Modern phyylogenetic comparative methods and their application in evolutionary biology. Springer, pp. 157-199.

Gómez, J. M. and Zamora, R. 2002. Thorns as induced mechanical defense in a long-lived shrub (Hormathophylla spinosa, Cruciferae). - Ecology 83: 885-890.

Gowda, J. H. and Palo, R. T. 2003. Age-related changes in defensive traits of Acacia tortilis Hayne. - Afr. J. Ecol. 41: 218-223.

Grubb, J. 1992. A positive distrust in simplicity lessons from plant defences and from competition among plants and among animals. - J. Ecol. 80: 585-610.

Guindon, S. and Gascuel, O. 2003. A simple, fast and accurate algorithm to estimate large phylogenies by maximum likelihood. - Syst. Biol. 52: 696-704.

Gutschick, V. P. 1999. Biotic and abiotic consequences of differences in leaf structure. - New Phytol. 143: 3-18.

Hallik, L. et al. 2009. Are species shade and drought tolerance reflected in leaf-level structural and functional differentiation in Northern Hemisphere temperate woody flora? - New Phytol. 184: 257-274.

Hanley, M. E. and Lamont, B. B. 2002. Relationships between physical and chemical attributes of congeneric seedlings: how important is seedling defence? - Funct. Ecol. 16: 216-222.

Hanley, M. E. et al. 2007. Plant structural traits and their role in anti-herbivore defence. - Perspect. Plant Ecol. Evol. Syst. 8: 157-178.

Hartley, S. E. and Jones, C. G. 1997. Plant chemistry and herbivory, or why the world is green. - In: Crawley, M. J. (ed.), Plant ecology, 2nd edn. Blackwell Publishing Ltd, pp. 284-324.

Heil, M. 2014. Herbivore-induced plant volatiles: targets, perception and unanswered questions. - New Phytol. 204: 297-306.

Hempson, G. P. et al. 2015. A continent-wide assessment of the form and intensity of large mammal herbivory in Africa. - Science 350: 1056-61.

Hempson, G. P. et al. 2017. The consequences of replacing wildlife with livestock in Africa. - Sci. Rep. 7: 17196.

Herms, D. A. and Mattson, W. J. 1992. The dilemma of plants: to grow or defend. - Q. Rev. Biol. 67: 283-335.

Kamilar, J. M. and Cooper, N. 2013. Phylogenetic signal in primate behaviour, ecology and life history. - Phil. Trans. R. Soc. B 368: 20120341.

Kariyat, R. R. et al. 2017. Plant spines deter herbivory by restricting caterpillar movement. - Biol. Lett. 13: 20170176.

Kellogg, A. A. et al. 2011. Morphological studies of developing Rubus prickles suggest that they are modified glandular trichomes. - Botany 89: 217-226.

Kitajima, K. and Poorter, L. 2010. Tissue-level leaf toughness, but not lamina thickness, predicts sapling leaf lifespan and shade tolerance of tropical tree species. - New Phytol. 186: 708-721.

Kitajima, K. et al. 2012. How cellulose-based leaf toughness and lamina density contribute to long leaf lifespans of shade-tolerant species. - New Phytol. 195: 640-652. 
0 Lajeunesse, M. J. and Fox, G. A. 2015. Statistical approaches to the problem of phylogenetically correlated data. - In: Fox, G. A. et al. (eds), Ecological statistics: contemporary theory and application, 1st edn. Oxford Univ. Press, pp. 261-283.

Lambers, H. and Poorter, H. 1992. Inherent variation in growth rate between higher plants: a search for physiological causes and ecological consequences. - Adv. Ecol. Res. 23: 187-261.

Mason, C. M. and Donovan, L. A. 2015. Does investment in leaf defenses drive changes in leaf economic strategy? A focus on whole-plant ontogeny. - Oecologia 177: 1053-1066.

10 Milewski, A. V et al. 1991. Thorns as induced defenses: experimental evidence. - Oecologia 86: 70-75.

Milton, S. J. 1991. Plant spinescence in arid southern Africa: does moisture mediate selection by mammals? - Oecologia 87: 279-287.

15 Mole, S. 1993. The systematic distribution of tannins in the leaves of angiosperms: a tool for ecological studies. - Biochem. Syst. Ecol. 21: 833-846.

Mole, A. S. and Waterman, P. G. 1987. A critical analysis of techniques for measuring tannins in ecological studies. I. Techniques. - Ecology 72: 137-147.

Moles, A. T. et al. 2013. Correlations between physical and chemical defences in plants: tradeoffs, syndromes or just many different ways to skin a herbivorous cat? - New Phytol. 198: 252-263.

Moore, K. J. and Jung, H.-J. G. 2001. Lignin and fiber digestion. - J. Range Manage. 54: 420.

Obeso, J. R. 1997. The induction of spinescence in european holly leaves by browsing ungulates. - Plant Ecol. 129: 149-156.

Onoda, Y. et al. 2017. Physiological and structural tradeoffs underlying the leaf economics spectrum. - New Phytol. 214: 1447-1463.

Orme, D. et al. 2018. caper: comparative analyses of phylogenetics and evolution in $\mathrm{R}$.

Osborne, C. P. et al. 2018. Human impacts in African savannas are mediated by plant functional traits. - New Phytol. 220: 10-24.

Pagel, M. 1999. Inferring the historical patterns of biological evolution. - Nature 401: 877-884.

Perez-Harguindeguy, N. et al. 2013. New handbook for standardised measurement of plant functional traits worldwide. - Aust. J. Bot. 61: 167-234.

40 Peschiutta, M. L. et al. 2018. Herbivory alters plant carbon assimilation, patterns of biomass allocation and nitrogen use efficiency. - Acta Oecol. 86: 9-16.

Pisani, J. M. and Distel, R. A. 1998. Inter- and intraspecific variations in production of spines and phenol in Prosopis caldenia and Prosopis flexuosa. - J. Chem. Ecol. 24: 23-36.

Poorter, H. et al. 2009. Causes and consequences of variation in leaf mass per area (LMA): a meta-analysis. - New Phytol. 182: 565-588.

Prins, H. H. T. and van der Jeugd, H. P. 1993. Herbivore population crashes and woodland structure in east Africa. - J. Ecol. 81: 305-314.

Rafferty, C. and Lamont, B. B. 2007. Selective herbivory by mammals on 19 species planted at two densities. - Acta Oecol. 32: $1-13$.

Read, J. et al. 2009. Correlations between leaf toughness and phenolics among species in contrasting environments of Australia and New Caledonia. - Ann. Bot. 103: 757-67.

Reich, P. B. 2014. The world-wide 'fast-slow' plant economics spectrum: a traits manifesto. - J. Ecol. 102: 275-301.
Reich, P. B. et al. 2012. The evolution of plant functional variation: traits, spectra and strategies. - Int. J. Plant Sci. 164: S143-S164.

Revell, L. J. 2012. phytools: an R package for phylogenetic comparative biology (and other things). - Methods Ecol. Evol. 3: 217-223.

Ripple, W. J. et al. 2015. Collapse of the world's largest herbivores. - Sci. Adv. 1: e1400103.

Rooke, T. et al. 2004. Defensive traits of savanna trees - the role of shoot exposure to browsers. - Oikos 1: 161-171.

Salguero-Gómez, R. 2017. Applications of the fast-slow continuum and reproductive strategy framework of plant life histories. - New Phytol. 213: 1618-1624.

Schindler, J. R. et al. 2003. Influence of thorns and tannins on white-tailed deer browsing after mowing. - J. Arid Environ. 55: 361-377.

Schmidt, M. et al. 2013. Geographical patterns of woody plants' functional traits in Burkina Faso. - Candollea 68: 197-207.

Scholes, R. J. and Walker, B. H. 2004. An African Savanna: synthesis of the nylsvley study. - Cambridge Univ. Press.

Shipley, B. 2006. Net assimilation rate, specific leaf area and leaf mass ratio: which is most closely correlated with relative growth rate? A meta-analysis. - Funct. Ecol. 20: 565-574.

Shipley, B. et al. 2006. Fundamental tradeoffs generating the worldwide leaf economics spectrum. - Ecology 87: 535-541.

Stamp, N. 2003. Out of the quagmire of plant defense hypotheses. - Q. Rev. Biol. 78: 23-55.

Staver, C. A. and Bond, W. J. 2014. Is there a 'browse trap'? Dynamics of herbivore impacts on trees and grasses in an African savanna. - J. Ecol. 102: 595-602.

Tindall, M. L. et al. 2016. Is there a latitudinal gradient in the proportion of species with spinescence? - Plant Ecol. 10: 1-7.

Tomlinson, K. W. et al. 2012. Biomass partitioning and root morphology of savanna trees across a water gradient. - J. Ecol. 100: 1113-1121.

Tomlinson, K. W. et al. 2014. Relative growth rate variation of evergreen and deciduous savanna tree species is driven by different traits. - Ann. Bot. 114: 315-324.

Tomlinson, K. W. et al. 2016. Defence against vertebrate herbivores trades off into architectural and low nutrient strategies amongst savanna Fabaceae species. - Oikos 125: 126-136.

Twigg, L. E. and Socha, L. V. 1996. Physical versus chemical defence mechanisms in toxic Gastrolobium. - Oecologia 108: 21-28.

van Soest, P. J. 1982. Nutritional ecology of the ruminant: ruminant metabolism, nutritional strategies, the celluolytic fermentation and the chemistry of forages and plant fibers. - $\mathrm{O}$ and B Books, Corvallis, OR.

Wallis, I. R. et al. 2012. Food for folivores: nutritional explanations linking diets to population density. - Oecologia 169: 281-291.

Westoby, M. et al. 2002. Plant ecological strategies: some leading dimensions of variation between species. - Annu. Rev. Ecol. Syst. 33: 125-159.

Wigley, B. J. et al. 2018. Defence strategies in African savanna trees. - Oecologia 187: 797-809.

Wright, I. J. et al. 2004. The worldwide leaf economics spectrum. - Nature 428: 821-827.

Young, T. P. and Okello, B. D. 1998. Relaxation of an induced defense after exclusion of herbivores: spines on Acacia drepanolobium. - Oecologia 115: 508-513.

Young, T. P. et al. 2003. Effects of natural and simulated herbivory on spine lengths of Acacia drepanolobium in on spine lengths of 
0 of natural and simulated effects herbivory in Kenya. - Oikos 101: 171-179.

Zhou, S. et al. 2015. Alteration of plant primary metabolism in response to insect herbivory. - Plant Physiol. 169: 01405.2015.

5 Supplementary material (available online as Appendix oik06960 at <www.oikosjournal.org/appendix/oik-06960>). Appendix 1.
Zuest, T. and Agrawal, A. A. 2017. Tradeoffs between plant growth and defense against insect herbivory: an emerging mechanistic synthesis. - Annu. Rev. Plant Biol. 68: 513-34.
61

65

70

75

15

10

80

20

25

35

40

30

100

45 


\section{Author Queries}

JOB NUMBER: 6960

JOURNAL: OIK_OIK

Q1 Please provide the significance of the bold text in the Table 2.

Q2, Q5 Please insert doi-number for Dryad Digital Repository: <http://dx.doi.org/10.5061/dryad.xxxxx>.

Q3 AQ: Update reference Archibald and Bond 2003

Q4 Please update the reference 'Armani et al. 2019'.

Q6 AQ: Publisher for Orme et al. 2018

Q7 AQ: Update volume for Rooke et al. 2004 